\title{
A utilização das Tecnologias de Informação e Comunicação na Educação Infantil: avanços e desafios
}

\author{
Elizabeth Carneiro Bergamasco, Leila Cristina Carneiro Bergamasco \\ Universidade de São Paulo - USP \\ \{bethberga@gmail.com, leilabergamasco@gmail.com\}
}

\begin{abstract}
Resumo: As Tecnologias de Informação e Comunicação (TICs) estão presentes no cotidiano da sociedade atual. A atual dinâmica da aprendizagem do aluno está interligada ao mundo mediático e a escola deve utilizar essa característica para motivar e interessar o corpo discente para novos saberes utilizando as TICs. O objetivo principal deste trabalho foi pesquisar o atual cenário sobre a utilização das TICs nas escolas de Educação Infantil, por meio de revisão bibliográfica, questionários e entrevistas com professores atuantes da rede municipal de ensino de São Paulo. Com os dados obtidos foi possível fazer uma análise sobre o atual processo de inclusão digital, observando quais as dificuldades e avanços no uso dessas ferramentas.
\end{abstract}

\begin{abstract}
The Information and Communications Technology (ICTs) are present in all sector of our society. In the school environment, the current dynamics of student learning is linked to the world media and the school should use this feature to motivate and interest the students to new knowledge using ICTs. The main objective of this study was to investigate the current scenario on the use of ICTs in childhood education, through literature review, questionnaires and interviews with teachers of municipal school network. With the data obtained, we can perform an analysis of the current process of digital inclusion, observing what difficulties and advances in the use of these tools.
\end{abstract}

\section{Introdução}

No Brasil, devido as suas peculiaridades políticas e estruturais, o processo da inclusão das Tecnologias da Informação e Comunicação (TIC) no contexto educacional foi muito lento e conturbado. Há questionamentos relevantes sobre sua eficiência e prioridade no processo de ensino e aprendizagem, em um país com tantas problemáticas de defasagens educacionais e de formação, o autor Valente (2004) ressalta:

"No Brasil, a área da Informática na Educação não seguiu um percurso diferente do que aconteceu em outros países mais desenvolvidos, embora tenha havido algumas peculiaridades: a defasagem no tempo, a velocidade de disseminação dos computadores nas escolas e um grande questionamento sobre a validade de uso de recursos tão dispendiosos em vista das necessidades e prioridades da Educação."

De acordo com Lopes et al. (2011), na realidade da Educação Infantil pública, a exclusão tecnológica se torna mais evidente, pois ainda está calcada em conteúdos tradicionais impostos por políticas públicas incoerentes. Dessa forma, a Educação 
Infantil está sendo privada de utilizar de forma didática as novas TICs aprimorando o processo pedagógico.

A Unesco alerta sobre as consequências dessa exclusão digital, pontuando que o Brasil precisa investir na formação dos professores para utilizar as TICs na educação [Unesco 2013].

Segundo Valente (1993) "para a implantação dos recursos tecnológicos de forma eficaz na educação são necessários quatro ingredientes básicos: o computador, o software educativo, o professor capacitado para usar o computador como meio educacional e o aluno, sendo que nenhum se sobressai ao outro".

O trabalho de Parette et al (2010) ressaltou que, já em 1996, a National Association for the Education of Young Children (NAEYC) - Associação Nacional para Educação de Crianças Pré Escolares, apontava que a escolha de um software educativo pelo professor é tão fundamental como a escolha de um livro para a leitura dos alunos.

O intuito desse artigo é apresentar o panorama de como as TICs estão sendo implantadas nas escolas de Educação Infantil no Município de São Paulo, pontuando seus avanços e desafios.

O presente artigo está organizado da seguinte forma: na Seção 2 são apresentados alguns trabalhos relacionados com o tema das TICs na Educação Infantil, a Seção 3 apresenta a Metodologia usada para a obtenção dos dados. A Seção 4 discute os resultados obtidos e a Seção 5 apresenta a conclusão do presente trabalho.

\section{Trabalhos Correlatos}

Inicialmente, foi realizada uma Revisão Sistemática (RS). A RS é uma metodologia de pesquisa desenvolvida para reunir e avaliar estudos relevantes relacionados a um determinado tema. O processo de condução da RS obedece a uma sequência bem definida de passos metodológicos, seguindo protocolos desenvolvidos com raciocínio a priori, o que a diferencia de revisões comuns, e uma estratégia de pesquisa bem definida e documentada [Kitchenham 2004].

Os trabalhos foram selecionados tendo por base palavras chaves: TICS, criança e Educação Infantil em português e inglês utilizando as bases de artigos ERIC (Eric Education Resource Center [ERIC 2012]), CAPES [CAPES 2012], RBIE (Revista Brasileira de Informática na Educação) [RBIE 2012], anais do SBIE (Simpósio Brasileira de Informática na Educação) [SBIE 2012] e os anais do WIE (Workshop de Informática na Educação) [WIE 2012] a partir dos critérios de inclusão e exclusão aplicados foram incluídos ao final do processo 10 trabalhos sendo 7 trabalhos estrangeiros e 3 nacionais.

Com os trabalhos analisados pela RS foi possível pontuar algumas considerações importantes em relação à formação, pesquisa e inovações no sentido de implementar o uso das TICs no universo da Educação Infantil como mais um mecanismo de aperfeiçoamento das práticas educativas. O'Hara (2008), observou que o uso de computadores e softwares educativos em uma sala de aula, ao contrário do que se acredita, não forma um indivíduo menos socializável.

O trabalho de Romeo et al. (2003) avaliou o uso de softwares educativos por meio de tablets em duas escolas americanas e concluiu que em relação a socialização e 
aprendizado da criança, essa ferramenta foi bastante adequada, despertando o interesse pelo uso. No entanto, verificou-se que a maioria dos softwares necessitam de adequação para essa faixa etária, principalmente em relação a disposição e tamanhos dos ícones.

Walters (2006) apresentou resultados positivos obtidos em sua classe do infantil, onde usou a câmera digital para registrar os momentos das crianças, permitindo que elas capturassem paisagens e ações dos colegas, criando histórias com as fotos por meio de slides.

No Brasil o trabalho de Tavares et al (2007), focou sua pesquisa na utilização de um programa de TV "A Turma da Árvore" junto ao contexto escolar, envolvendo a participação e acompanhamento de professores e alunos de três escolas brasileiras, da cidade de Salvador, conjunto de especialistas em software, pedagogos, comunicadores e autores do programa de TV, tendo uma resposta positiva no que tange a integração escola e programas interativos na TV, porém ainda pouco difundido devido ao alto custo e a necessidade de desenvolvimentos de softwares adequados.

O uso da Lousa Digital Interativa por profissionais da Educação Infantil foi apresentado no trabalho de Gomes (2011) onde realizou uma análise sobre a oficina de formação de professores, sobre o uso da lousa digital interativa na Educação Infantil, dificuldades e benefícios. No trabalho de Nakashima e Amaral (2006), como um instrumento para a inserção da linguagem audiovisual no contexto escolar, seu uso prático na preparação e utilização nas práticas pedagógicas em sala de aula.

Ambos retrataram a realidade brasileira, e tiveram resultados positivos no que tange a interação com os alunos, porém salientou o número reduzido dessas lousas nas escolas; a formação dos professores no seu uso, a quantidade reduzida de softwares que existem no contexto infantil, limitando as abordagens em que podem ser usadas. 


\section{Metodologia}

Para alcançar os objetivos da pesquisa, decidiu-se por uma abordagem quantitativo-qualitativa, que possibilita uma triangulação dos dados, onde os resultados qualitativos se apoiam nos resultados quantitativos e vice-versa, fornecendo um quadro mais amplo sobre a problemática levantada [Flick 2009].

O processo de investigação foi realizado por meio de dois questionários e aplicado em 12 professores de Centro de Educação Infantil (CEI) e 12 professores de Escola Municipal de Educação Infantil (EMEI), respondendo a 10 questões fechadas com opção de escolha com cinco graus de concordância, referentes ao conhecimento, formação, postura e opinião sobre os equipamentos tecnológicos presentes na escola e a utilização das TICs no processo ensino aprendizagem. Outros 12 professores responderam um questionário com 10 questões abertas em forma de entrevista focando o conhecimento e utilização das TIC na rotina diária de casa e da escola. Foram selecionadas 20 escolas no total, 10 de CEI e a 10 de EMEI, todas localizadas no munícipio de São Paulo, utilizando as homepages das escolas, e-mails, redes sociais para enviar e receber os questionários.

Após a coleta de informações foi realizada a tabulação dos dados para a análise, as informações foram separadas em categorias, permitindo visualizar as especificidades de cada uma e analisar com mais rigor estas informações.

\section{Resultados e Discussões}

Conforme discutido anteriormente, as informações obtidas por meio de questionários e entrevistas foram separadas em categorias para promover uma discussão mais completa dos resultados.

As escolas selecionadas estão localizadas em na região leste do Munícipio de São Paulo, todos os participantes foram do sexo feminino, uma característica marcante na modalidade da Educação Infantil. As participantes possuem idade entre 31 a 54 anos e lecionam entre 3 a 35 anos, ou seja, a amostragem de participantes foi bastante diversificada no que tange a experiência em sala de aula, favorecendo a discussão do uso das TICs sob diferentes perspectivas. Nas próximas seções serão discutidos aspectos específicos obtidos por meio dos questionários e entrevistas nos diferentes ambientes escolares.

\subsection{Conhecimento sobre as TICs}

Nesta categoria, dentre as tecnologias apresentadas, a Internet é a mais conhecida pelos entrevistados, seguida pelos computadores e impressora. Um aspecto relevante que se observou foi que as tecnologias mais conhecidas são usadas também no ambiente doméstico. Já a lousa digital, que é um equipamento bastante específico para a didática na sala de aula era conhecida por apenas $5 \%$ dos entrevistados. 


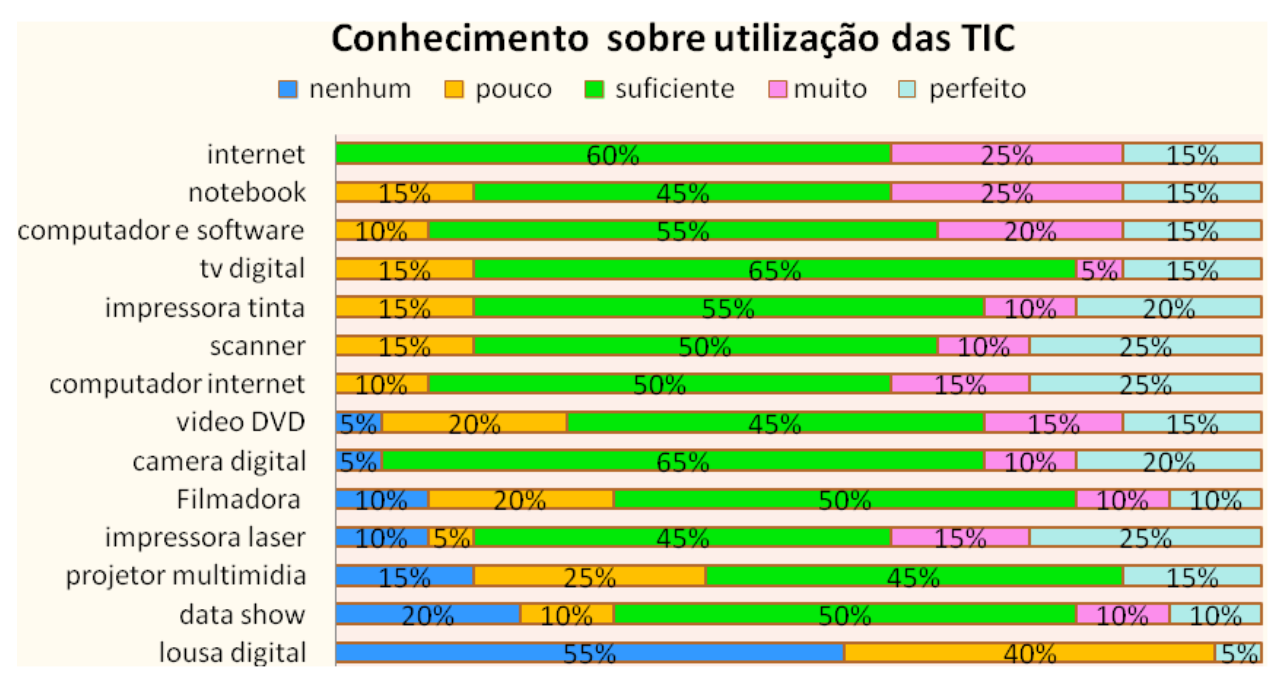

Figura1. Distribuição dos níveis de conhecimento dos professores sobre diferentes TICs.

A formação do professor é um ponto relevante no que tange ao uso das TICs em sala de aula. Quando questionados sobre esse aspecto, 95\% dos sujeitos entrevistados concordam que gostariam de aprender mais sobre o uso das TICs na Educação Infantil, $5 \%$ concordam em parte. Quanto à questão da formação acadêmica, $95 \%$ dos sujeitos ressaltam que os currículos de licenciatura deveriam ser reformulados objetivando o conhecimento e utilização nas práticas pedagógicas. Sobre esse assunto, os trabalhos de O'Hara (2011) e Nikopopoulos e Gialamas (2007) identificaram que os professores aprovaram o uso das TICs, porém existe uma lacuna que é a formação sobre o seu uso. Os professores desejam mais aulas práticas em seus cursos de Graduação ou Especialização usando as novas tecnologias, e que estas sejam mais realistas, e tenham seu conteúdo adaptado as novas tendências midiáticas. Sobre a resistência dos professores em utilizar as TICs em suas práticas pedagógicas seja devido à falta de formação, $65 \%$ apontaram que concordam com essa afirmação e $35 \%$ concordam em parte.

O gráfico da Figura 2 mostra que a opinião do professorado corrobora os trabalhos citados anteriormente. 


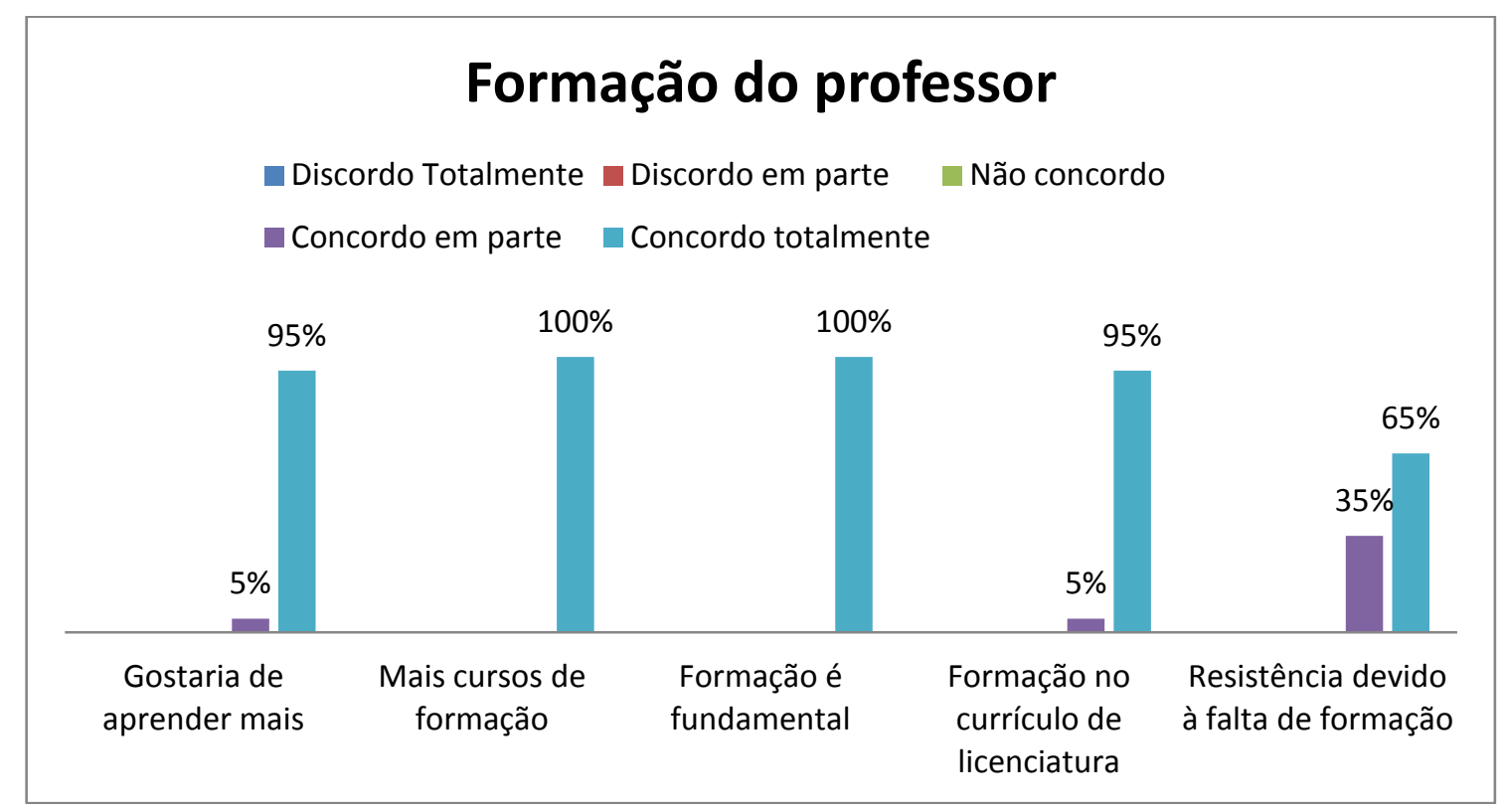

\section{Figura 2. Opinião sobre a atual formação dos professores em relação às TICs.}

Sobre a postura do professor em relação às TICs, os resultados mostraram que $95 \%$ dos sujeitos gostam de trabalhar com as TICs por ser desafiador e estimulante. Os $5 \%$ dos sujeitos que alegam não serem bons para lidar com as tecnologias, demonstram insegurança e tensão, pois a falta de conhecimento sobre os equipamentos prejudica a utilização refletindo no posicionamento pessoal do professorfrente as TICs. O Gráfico da Figura 3 apresenta a distribuição dessas opiniões.

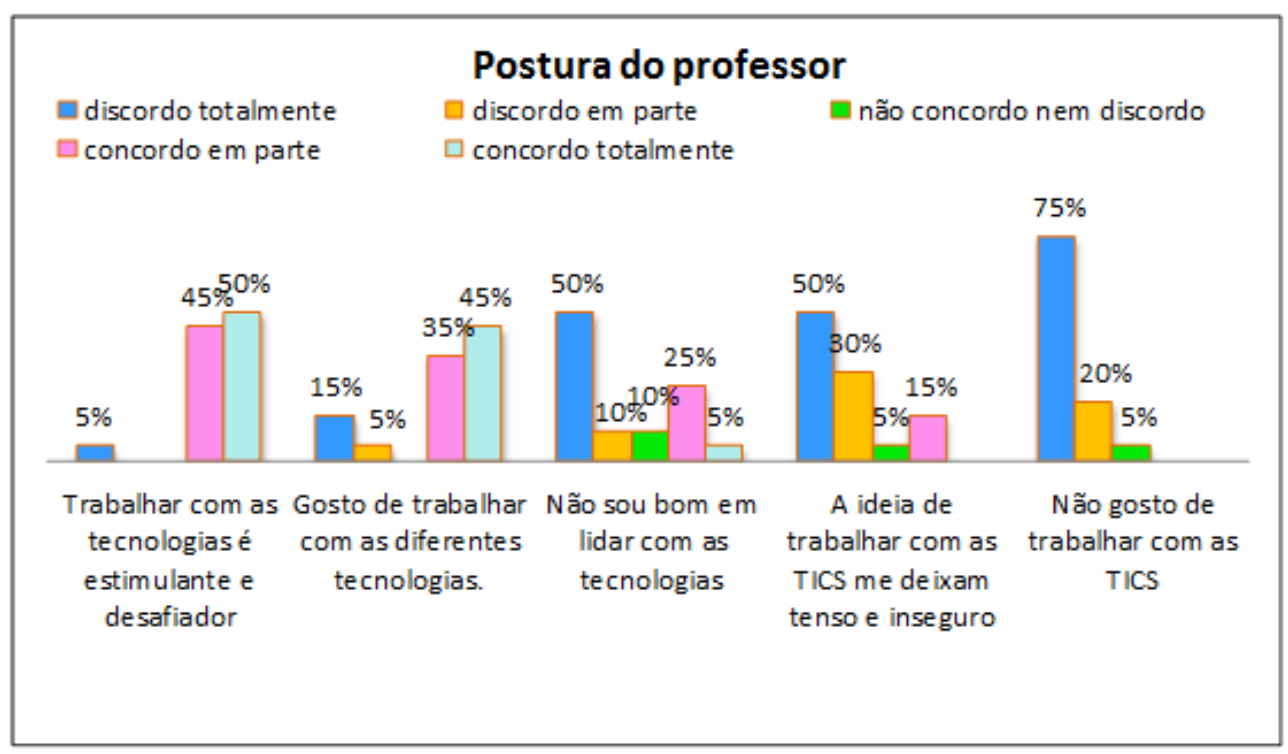

Figura 3. Opinião dos professores sobre a postura frente o uso das TICs no cotidiano.

Em relação a percepção sobre o uso das TICs no cotidiano escolar infantil, o gráfico da Figura 4 apresenta que $90 \%$ dos sujeitos alega que as escolas de Educação Infantil estão desprovidas de equipamentos adequados a criança de zero a seis anos, devido a um descaso das políticas públicas educacionais e de não promover formação 
adequada aos professores, mantendo as crianças e os professores excluídos do processo de inclusão digital.

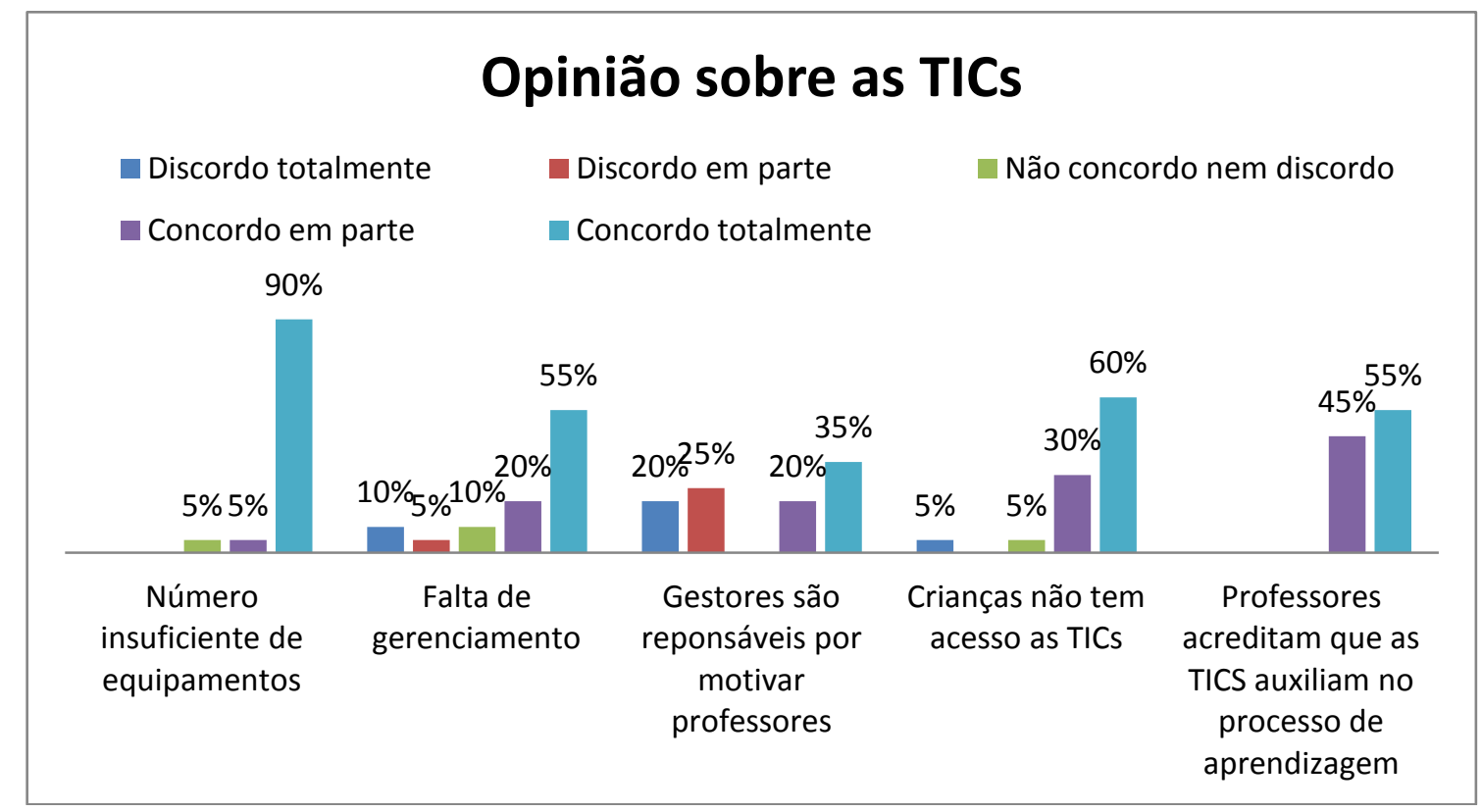

Figura 4. Percepção dos professores em relação ao uso das TICs no cotidiano escolar.

A opinião sobre os equipamentos disponíveis para a educação infantil, 95\% dos entrevistados afirmam que são insuficientes para realizar um trabalho mais abrangente, $5 \%$ concordam em parte e $5 \%$ não tem opinião sobre o assunto, mostrando que há uma constatação real da problemática das TICs nas escolas de educação infantil. Notou-se também que 55\% dos entrevistados têm uma visão critica sobre os gerenciadores da educação nesse nível de ensino, pois acreditam que estes, não equipam as escolas condizentemente visando a inclusão digital e tecnológica nesta faixa etária, 10\% porém discordam totalmente, porém sem justificar, 35\% nessa questão pontuaram opiniões pouco conclusivas. Na questão sobre o acesso da criança a computadores e internet, $60 \%$ afirmam que estas não tem acesso, mostrando um alto índice de exclusão digital, $5 \%$ discordam totalmente apontando que algumas poucas escolas possuem esse acesso, $30 \%$ concorda em parte, pois em alguns momentos as crianças utilizam os equipamentos, na sala de informática. As questões sobre a visão que os entrevistados tem sobre o quanto as TICs auxiliam no processo de ensino e aprendizagem, constou-se que $55 \%$ concordam plenamente, demonstrando uma constatação da realidade mediática das crianças no mundo atual, porém $45 \%$ concorda em parte, pontuando uma mescla de utilização.

De acordo com Moran (2009) o futuro será promissor, dependendo das posturas tomadas hoje. "Ensinar com as novas mídias será uma revolução, se mudarmos simultaneamente os paradigmas convencionais do ensino, que mantêm distantes professores e alunos. Caso contrário, conseguiremos dar um verniz de modernidade, sem mexer no essencial."

\subsection{Entrevistas}

Os resultados mostram que $100 \%$ dos sujeitos possuem e utilizam o computador em suas residências, para realizarem seus trabalhos profissionais e particulares. A 
formação individual é uma preocupação dos sujeitos para o aprimoramento de suas práticas. A utilização do computador e da internet como meio de comunicação social é uma marca predominante em 100\% dos entrevistados, demonstrando conhecimento sobre essa ferramenta.

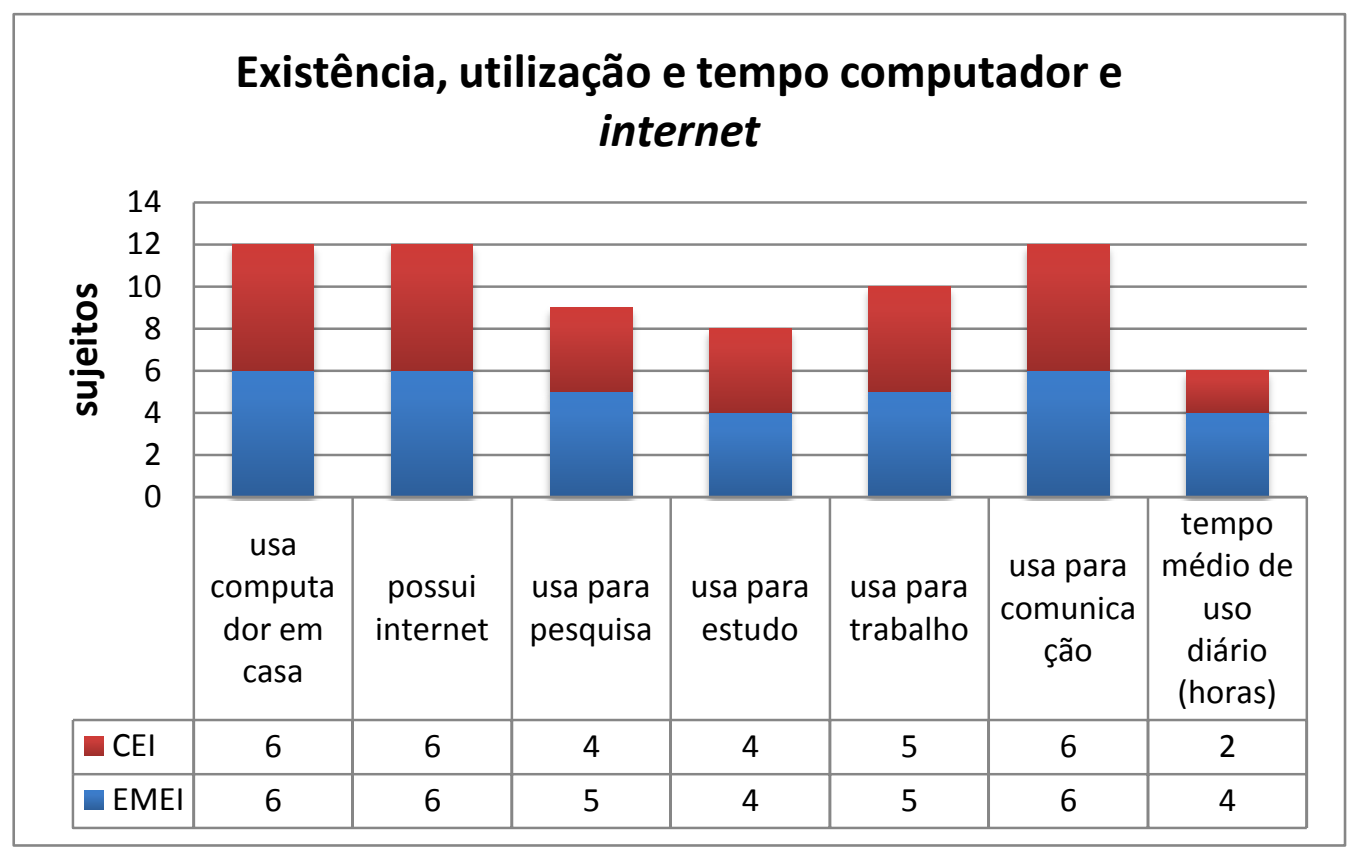

Figura 5. Perfil de utilização das TICs pelos professores.

Para a pergunta sobre a facilidade em manusear os equipamentos tecnológicos disponíveis na escola, os sujeitos da EMEI afirmam que o manuseio é fácil e que as tecnologias disponíveis são variadas, em número adequado a demanda. Esse cenário, no entanto, não foi relatado no CEI, relacionado a falta de computadores, abaixo do número necessário para o acesso de todas as crianças e professores, estando localizados, em sua maioria, nas áreas administrativas.

$\mathrm{Na}$ EMEI, é percebido que oprocesso de inclusão digital está mais avançado devido ao fato de ter pessoal especializado para manusear esses equipamentos, é possível utilizar a sala de informática, câmeras e vídeos, para realizarem trabalhos educativos através de jogos, motivando novas aprendizagens. De acordo com um relato de um sujeito entrevistado da EMEI: "[...] as aulas ficam mais produtivas, motivadoras, as crianças adoram.", diferentemente do que apontou três sujeitos entrevistados do CEI: "Não temos computadores nas salas de aula, só tem na secretaria"; "[...] só utilizamos o projetor multimídia uma vez por semana, para exibir filmes"; "Tem um rádio da sala; [...] mesmo assim as crianças gostam muito".

Com relação às TICs na rotina escolar no CEI, os sujeitos apontaram sucateamento e carência de equipamentos adequados a essa faixa etária, formação adequada para o uso das TICs no cotidiano e nas práticas pedagógicas. Os sujeitos da EMEI enfatizaram positivamente, "Já faz parte da rotina escolar [...]; [...] os resultados são significativos; [...] a sociedade exige a inclusão digital desde a Educação Infantil”".

A última pergunta, sobre a importância das TICs revelou o seguinte comentário de um sujeito entrevistado da EMEI: "[...] nos dias atuais não é mais possível dar aulas só dependendo da lousa e do giz.", enquanto que um sujeito do CEI ressaltou a 
importância das TIC reivindicando a oportunidade de utilizá-las "O CEI não pode ser excluído do processo de inclusão digital, pois tudo é voltado para as EMEI e EMEF”.

\section{Conclusões}

A Educação Infantil se propõe a atender crianças de zero a seis anos com o máximo de qualidade, mas ainda enfrenta grandes desafios. Os relatos dos sujeitos entrevistados e os documentos pesquisados ressaltam a importância da utilização das TICs na Educação Infantil, propondo a dinamização das experiências e conteúdos.

As considerações sugerem novas posturas visando, se não acabar, minimizar os desafios para que a utilização das TICs consiga atingir o propósito de propiciar novos caminhos para a criança da Educação Infantil, vivenciar novos saberes. Não é necessário copiar exemplos alheios a nossa realidade, pois existem experiências enriquecedoras, o que falta são políticas publicas coerentes para implementar o que a legislação já contempla: as TICs nos ambientes de Educação Infantil, propiciando experiências de práticas exequíveis nos cursos de formação e nos documentos idealizados para esse fim. A insegurança de muitos professores em utilizar as TICs no cotidiano escolar se deve a falta de conhecimento e a impossibilidade de unir essas tecnologias à realidade pedagógica, analisando as entrevistas realizadas. Destaca-se Fiorentini e Lorenzato (2006), que aponta uma preocupação pertinente em relação a inclusão das TICs no contexto escolar:

(...) parece haver uma crença, entre alguns responsáveis pelas políticas educacionais, de que as novas tecnologias da informação e comunicação são uma panacéia para solucionar os males da educação atual. [...] se, de um lado, pode ser considerado relativamente simples equipar as escolas com essas tecnologias, de outro, isso exige profissionais que saibam utilizá-las com eficácia na prática escolar.

Muitas situações de desconhecimento sobre a utilização dos equipamentos das TICs no ambiente escolar são identificadas, indicando a não apropriação das TICs na prática pedagógica. Principalmente no CEI, a não utilização das TICs é mais marcante, devido à inclusão recente na Educação Infantil. Na rotina escolar foram obervados alguns problemas como a deficiência na formação do professor e, principalmente, o sucateamento e até mesmo ausência de equipamentos e ferramentas relacionadas as TICs, provocando o adiamento da inclusão digital nos CEI.

Um ponto afirmativo é a consciência positiva por parte dos professores, que a utilização das TICs na Educação Infantil seria um acréscimo as aprendizagens, e decorrente a isso, estes professores promovem suas formações e utilizam dentro das possibilidades assertivas que as TICs proporcionam em suas práticas educativas.

Outro aspecto interessante foi verificar o quão novo esse assunto é para a Educação Infantil na realidade brasileira, pois no escopo pesquisado, poucos trabalhos tratavam do assunto referente a alguma experiência sobre o uso de alguma TIC em sala de aula com alunos da Educação Infantil, diferentemente do número de trabalhos encontrados nas pesquisas em outros países. Isto vai de encontro à problemática da novidade das TIC na Educação Infantil no Brasil, demonstrando um potencial alto para futuras pesquisas sobre as experiências produtivas utilizando as TIC e nova práticas de ensino e aprendizagem. 


\section{Referências}

CAPES. Portal Periódicos CAPES. Disponível em: www.periodicos.capes.gov.br. Acessado em: 10/2012.

ERIC. Educational Resource Information Center. Disponível em: www.eric.ed.gov. Acessado em: 10/2012.

FLICK, U. Introdução à pesquisa qualitativa. $2^{\mathrm{a}}$ ed. São Paulo: ARTMED, 2002, p. 408.

FIORENTINI, D.; LORENZATO, S. Investigação em Educação Matemática: percursos teóricos e metodológicos. Campinas, SP: Autores Associados. 2006, p. 226.

GOMES, E. M. Uma experiência com o uso da Lousa Digital Interativa por profissionais da Educação Infantil. Educação Temática Digital. Faculdade de Educação UNICAMP: Campinas/SP, v. 12, p. 268-289. 2011.

KITCHENHAM, B. Procedures for performing systematic review. Technical Report TR/SE-0401, Keele University. 2004.

LOPES, A. F; SANTOS, E. M. B. R. do.; FERREIRA, P. J. S.; BRITO, P. V. G. O desafio das TICs na Educação Infantil. Revista Pandora Brasil. Universidade Mackenzie, n. 34, p. 170-184. 2011.

MORAN, J. M; MASETTO, M.; BEHREnS, M. Novas Tecnologias e Mediação Pedagógica. 16 a ed. Campinas: Papirus, 2009, p.11-65.

NAKASHIMA, R. H. R; AMARAL, S. F. do. A Linguagem Audiovisual da Lousa Digital Interativa no Contexto Educacional. Educação Temática Digital. Faculdade de Educação UNICAMP: Campinas/SP, v. 8, n.1, p. 33-48. 2006.

NIKOLOPOULOU, K.; GIALAMAS V., In-service and pre-service early childhood teachers' views and intentions about ICT use in early childhood settings: A comparative study. Computers \& Education. Elsevier, v.55, p. 333-341. 2010.

O'HARA, M. Young children, learning and ICT: a case study in the UK maintained sector. Technology, Pedagogy and Education. Taylor \&Francis, v.17, p. 29-40. 2008. 
PARETTE, H. P.; BOECKMANN, N. M.; HOURCADE, J. J. Use of Writing with Symbols 2000 Software to Facilitate Emergent Literacy Development. Early Childhood Education Journal. Springer, v. 36, n. 2, p. 161-170. 2010.

RBIE. Revista Brasileira de Informática na Educação. Disponível em: http://www.cbie.org.br/index.php/rbie. Acessado em: 10/2012.

ROMEO, R.; EDWARDS, S.; MCNAMARA S.; WALKER, I.; ZIGURAS C. Touching the screen: issues related to the use of touchscreen technology in early childhood education. British Journal of Educational Technology. Wiley, v. 34, n. 3, p. 329-339. 2003.

SBIE. Anais do Simpósio Brasileiro de Informática na Educação. Disponível em: http://www.cbie.org.br/index.php/anaissbie. Acessado em: 10/2012.

UNESCO, Políticas em ciência e tecnologia no Brasil. Brasil, 2013 Disponível em: http://www.unesco.org/new/pt/brasilia/natural-sciences/science-and-technology/science-andtechnology-policy/. Acessado em 05/2013.

TAVARES, T. A.; SANTOS, C. A. S., T. R.; PINHO, C. B. B.; CARVALHO, G. M.; COSTA, C. S. A TV Digital Interativa como Ferramenta de Apoio à Educação Infantil. Revista Brasileira de Informática na Educação, v. 15, n. 2, p. 32-44. 2007.

VALENTE, J. A. Computadores e conhecimento: repensando a educação. Campinas: UNICAMP. 1993, p. 142.

Pesquisa, comunicação e aprendizagem com o computador: o papel do computador no processo ensino-aprendizagem. In: ALMEIDA, M. E. ; MORAN, J. M. Integração das tecnologias na educação . Brasília : MEC/SEED, 2005. p. 22-31.

WALTERS, K. Capture the moment: Using digital photography in early childhood settings. Research in Practice Series. Early Childhood Australia, v.13, n.4, p. 1-22. 2006.

WIE. Anais do Workshop de Informática na Educação. Disponível em: http://www.cbie.org.br/index.php/anaiswie. Acessado em 10/2012. 